Acta Poetica $35 \cdot 2$

JULIO-DICIEMBRE

$2014(169-186)$

\title{
El oído interior. Acerca del encuentro de Cristina Campo, María Zambrano y Marius Schneider
}

\author{
Victoria Cirlot
}

El presente texto trata sobre el encuentro, tanto anecdótico como teórico, de Cristina Campo, María Zambrano y Marius Schneider. La autora remite a los indicios del contacto entre los tres (la colaboración en las revistas Sur y Conoscenza religiosa, la frecuentación de Campo y Schneider, la correspondencia entre ella y Zambrano), no obstante, también señala el interés compartido por el órgano del oído, además de similitudes en el pensamiento desde sus respectivas disciplinas: el acercamiento simbólico al órgano auditivo, su superioridad sobre la visión, las asociaciones entre música y palabra, la antítesis entre música y piedra, la complementación entre oído interno y destino, así como la necesidad de una audición atenta para escuchar la voz interior y el propio destino. En el caso de Cristina Campo, también se discute la musicalidad de su estilo de escritura.

PALABRAS CLAVE: encuentro, oído, interior, música, destino.

This text concernes the encounter, anecdotic as well as theoric, of Cristina Campo, María Zambrano and Marius Schneider. The author refers to the inklings of the contact between them (the colaboration in Sur and Conoscenza religiosa magazines, the frequenting of Campo and Schneider, the correspondence between her and Zambrano), nevertheless, she also signs the shared interest in the organ of hearing, in addition to the similarities of thought from their respective disciplines: the symbolic approach to the auditive organ, its superiority over vision, the associations between music and word, the antithesis among music and stone, the complementing between internal hearing and destiny, as well as the need of an attentive audition to listen to the internal 
voice and one's destiny. In the case of Cristina Campo, the musicality of her writing style is also discussed.

KEYWORDS: encounter, hearing, internal, music, destiny.

Fecha de recepción: 6 de febrero de 2014

Fecha de aceptación: 15 de marzo de 2014

170 СіRLOT / El oído interior. Acerca del encuentro de Campo, Zambrano y Schneider 


\section{Victoria Cirlot \\ Universitat Pompeu Fabra, Barcelona \\ El oído interior. Acerca del encuentro de Cristina Campo, María Zambrano y Marius Schneider}

En el ensayo que lleva por título La flauta y la alfombra dentro del volumen publicado póstumamente con el título de Los imperdonables, Cristina Campo cita una expresión de Boris Pasternak para proporcionar visibilidad a quienes reconocen haber perdido el propio destino como aquellos mutilados del "oído del alma". Se inscribe esta expresión en una antigua y muy rica tradición de la cultura europea, la de los sentidos interiores o como ella los llamó en otro ensayo del mismo volumen, los sentidos sobrenaturales. En la escritura de Cristina Campo puede reconocerse un oído finísimo, tal es la seda de su prosa (Spina, Conversazione in piazza sant 'Anselmo, 19); ${ }^{1}$ el mismo oído por el que ella reconocía de inmediato a "los imperdonables"; el oído ejercido en una familia de músicos - "nacida en una familia de músicos”, así se presentaba a sí misma-; el oído, en fin, que oye la voz del destino. La facultad auditiva abre una puerta por la que entrar en el mundo de Cristina Campo. Un mundo poblado por seres de luz, florecidos en la imaginación y en la lectura (Zambon, “ 'Il mundus imaginalis' de Cristina Campo", 18-23), ${ }^{2}$ también un mundo de amigos con los que mantenía conversaciones infi-

1 "Cristina diceva di avere per la lingua italiana l'orecchio assoluto. Attilio Bertolucci ha parlato di una prosa di seta".

2 En el sentido corbiniano de mundo entre tierra y cielo. Agradezco a Francesco Zambon que me diera a conocer a Cristina Campo. 
nitas de las que sobre todo se recuerda su voz de cristal, clara y transparente. ${ }^{3}$ Entre esos últimos, dos compañeros privilegiados del oído interior de Cristina Campo: uno de ellos, el musicólogo y etnólogo Marius Schneider, el otro, la filósofa andaluza María Zambrano. La constelación de esta tríada tiene su origen en un hecho anecdótico y coincidente: Zambrano traducirá al castellano uno de los ensayos de Campo para la revista argentina Sur, donde también aparecerá un ensayo de Schneider, el más revelador de la empatía entre ambos. La coincidencia no será banal, sino todo lo contrario. Los tres están unidos además por la atención a ese misterioso órgano y a su funcionamiento. Sus distintos lenguajes (musicológico-etnológico, filosófico, ensayístico), iluminan mutuamente su significado y en el caso de la Campo permitirá ahondar en el valor de su estilo, el de alguien que afirmó "que había escrito poco, pero que le habría gustado haber escrito aún menos".

"También quería a Murena porque había entrado en nuestra vida en el mismo periodo en el que entraste tú, en que entró Marius Schneider - aquel tiempo de inicios maravillosos, de plena juventud”. Este fragmento pertenece a una carta dirigida a María Zambrano fechada en la fiesta de san Juan de 1975. ${ }^{4}$ En ella, Cristina Campo lamenta la muerte de Héctor Murena, poeta amigo, fallecido, dice, el 5 o 6 del pasado mes con 52 años. En su recuerdo, Murena, Schneider y Zambrano entran en "nuestra vida" (el plural, incluye aquí a Elémire Zolla) en la misma época, es decir, en "los tiempos de inicios maravillosos, de plena juventud". Son también esos los inicios de su relación con Zolla, finales de los años cincuenta, cuando ella todavía se siente en "plena juventud", sin todavía haber alcanzado la cuarentena — había nacido el 29 de abril de 1923 - cuando se renuevan los intereses, las pasiones, las actividades. Es, pues, en un tiempo de renacimiento en el que Cristina

3 Dos referencias; la primera en la carta de Enrique de Rivas a María Zambrano del 12 de enero de 1977: "De ella recuerdo aquella voz de cristal única, que era como agua alegre..." (Campo, Se tu fossi qui. Lettere a Maria Zambrano. 1961-1975,12); la segunda de Alessandro Spina, que habla de la "nostalgia di quella voce pura" (14).

${ }^{4}$ Agradezco a Jesús Moreno Sanz que me proporcionara fotocopias de la correspondencia entre María Zambrano y Cristina Campo que se encuentra en la Fundación Zambrano de Vélez (Málaga); pocos días después de recibirla, encontré el libro de Maria Pertile, Se tu fossi qui, citado. Todas las traducciones de las citas son mías excepto las que pertenecen a pasajes de Los imperdonables. 
Campo sitúa su encuentro con Marius Schneider y María Zambrano. La relación entre Cristina Campo y María Zambrano ha sido estudiada (cfr. Pertile en Campo, Se tu fossi qui, 83) en cambio, su relación con Schneider ha permanecido en la sombra. Huellas casi imperceptibles, como el fragmento citado, o como otro pasaje en una carta a su amiga Margherita Pieracci, Mita, en el que menciona las rosas pálidas que Schneider recibiera después de una conferencia en Roma y que le regalara el mismo día de su cumpleaños, sin saberlo: "il bel fiore sulla sua lettera - una peonia? - si è unito alle rose pallide che Schneider (quello del canto gregoriano) aveva ricevuto per la sua conferenza a Roma e mi aveva pórtate" (Campo, Lettere a Mita, 192; 29 de abril de 1965). Schneider es "el del canto gregoriano", "el que ha publicado el gran ensayo sobre el gregoriano", como le dice a Alessandro Spina en una carta de 1964. ${ }^{5}$ Como ella misma se presentaba en las breves biografías que acompañaban a sus artículos o a sus libros como "la que se ocupa del canto gregoriano". ${ }^{6}$ No es ésta una seña de identidad insignificante para quien, como Cristina Campo, se revolvió activamente contra el concilio vaticano II por la exigencia absoluta de defender la misa en lengua latina y tuvo que refugiarse en el ritual bizantino del Russicum como el último lugar en que reconocía la belleza de la liturgia (cfr. Farnetti, Cristina Campo, 55 y ss.). En una carta a Leone Traverso del 28 de abril de 1965 describía a Schneider como "un gran león, poderoso y tranquilo" (Caro Bull, 131) ${ }^{7}$

Marius Schneider (1903-1982) había publicado en la revista Elsinore un ensayo sobre el canto gregoriano en 1964, en el mismo número

5 "Riceverà l'ultimo numero di Elsinore. Lo accolga come una mia lunga lettera. Sopratutto le due traduzioni di H. (la prima poesía, l'ultima strofa), il grande saggio di Schneider sul gregoriano" (Campo, Lettre a un amico lontano, 98).

${ }^{6}$ Así, por ejemplo en el primer número de Conoscenza religiosa $(1,1969)$ donde publica su poema Missa Romana, su biografía dice: "Cristina Campo es un pseudónimo. Pertenece a una familia de músicos y hombres de ciencia. Ha publicado en Italia y en el extranjero poesías y ensayos sobre todo en torno a los cuentos (Passo d'addio, Milán 1953; Fiaba e mistero, Florencia, 1963; Gli imperdonabili, en prensa). Ha traducido a John Donne, W.G. Williams, y la tragedia en versos de Simone Weil, Venezia salva. Suya es la introducción a la Storia della Città di Rame, Milán, 1964. Se ocupa del canto gregoriano".

7 "Spero tu possa assistere al Simposio di Sabato. Schneider è veramente un grande leone, possente e calmo". 
en que Cristina Campo publicara por vez primera el ensayo titulado Una divagación, posteriormente incorporado a Los imperdonables. Un ensayo sobre el canto gregoriano fue publicado en castellano en el número enero-febrero de 1965 en la revista Sur ("Consideraciones acerca del canto gregoriano y la voz humana”, 4-20), ${ }^{8}$ la que fundó Victoria Ocampo en Buenos Aires en 1931 y que habría de acoger las primeras versiones castellanas de Cristina Campo, una de ellas debida justamente a María Zambrano. En 1961, en el número de julio y agosto, aparece Atención y poesía traducido por la Zambrano, al que siguieron otros como In medio Coeli (1962), Les sources de Vivonne (1964), Los imperdonables (1966). ${ }^{9}$ La revista Sur amplió los lectores de la Campo. Ella que, como Hoffmansthal, decía escribir sólo para dos o tres personas, se encontró, por ejemplo, con un lector desconocido y apasionado por su texto In medio Coeli y que había conocido gracias a Sur. ${ }^{10} \mathrm{Y}$ fue ese espacio lejano, para todos extranjero, en el que coincidieron Schneider, la Campo y la Zambrano, en el espacio de las letras para las que el oído interior es la facultad superior. Del gran ensayo de Marius Schneider sobre el canto gregoriano entendido como una forma de oración, sólo citaré dos pasajes en los que de inmediato asoma la inevitable conexión con el pensamiento de Cristina Campo. Dice así: “Con todo sería erróneo pensar que por esto los movimientos musicales del canto gregoriano es-

${ }^{8}$ Ver arriba. Supongo que se trata del mismo artículo, pero no he podido ver el de Elsinore. No figura nombre de ningún traductor.

9 Cristina Campo, “Atención y poesía", 38-41; "In medio Coeli”, trad. Pedro J. Albertelli, Sur, julio y agosto 1962, 30-40; "Les sources de la Vivonne", trad. M.L. Bastos y Eugenio Guasta, Sur, marzo y abril 1964, 24-28; "Los imperdonables" (no consta el nombre del traductor), Sur, julio y agosto 1966, 60-70.

${ }^{10}$ En una carta a Leone Traverso del 24 de agosto de 1962: "Questo saggio [In Medio Coeli ] ha avuto pocchissimi lettori. Sembra che in Italia per cose di questo genere non ci sia diritto di cittadinanza 'Sur', invece, lo ha accolto e pubblicato con la solita naturalezza" (Caro Ball, 116). También fue publicado en alemán en Antaios, marzo de 1967 (581-94), la revista fundada por Ernst Jünger y Mircea Eliade, y en la que publicó Marius Schneider. En una carta a Mita del 3 de noviembre de 1962: "E da Parigi un ragazzo che aveva letto In medio coeli in 'Sur', mi ha mandato un biglietto: 'Le offro la mia amicizia per quanto [ci] rimane di vita"” (170), y en otra carta del mismo mes: "Quando va a Parigi? Volevo darle l'indirizzo di un amico (un ragazzo che mi ha scritto su In medio coeli- glielo aveva detto?) malato e solo pieno di una meravigliosa felicità. Una persona che fa quasi paura, tanto riesce a mutare in felicità tutto quello che tocca. Sta in rue Jacob 19, si chiama Calveya" (Lettere a Mita, 173). 
tén en contradicción con las leyes musicales de la gravedad; pues, muy al contrario siguen respetando dichas leyes, pero sus arcos melódicos les quitan la pesantez y cuanto en ellas pudiera haber de rudimentario y de tosco; ensanchan el ritmo de sus evoluciones en forma análoga a la de un arco, que permite ampliar la distancia entre las columnas bajo el techo de un templo." (“Consideraciones”, 5). El canto gregoriano se entiende aquí como un milagro de la gracia que se eleva en vuelo aun respetando las leyes de la gravedad, términos que asociamos al pensamiento weiliano, la autoridad indiscutible para Cristina Campo junto con Hugo von Hoffmansthal, Proust y Gottfried Benn, primer círculo en la clasificación de Monica Farnetti. ${ }^{11}$ La segunda cita no puede ser más afín a la "ideología" de Campo: "La fuerza de expresión del canto gregoriano no se verifica por paroxismo, sino por la sobriedad, la cortesía y la castidad de sus fórmulas" (“Consideraciones", 6). Los tres atributos, sobrio, cortés, casto, aplicados al canto gregoriano, con toda su aparente contradicción y fuerza de oposición, podrían aplicarse igualmente a la misma persona de Cristina Campo. En el bellísimo retrato que le dedicó Pietro Citati, se nos advertía que no miráramos la fotografía que acompañó la publicación de Los imperdonables en la edición de Adelphi de 1987, en donde aparecía como "una señorita de los años cincuenta apenas salida de la peluquería", sino que para ver a la verdadera Cristina Campo miráramos la cubierta del libro: "la donatrice col lungo capello nero, il vestito nero, l'ermellino, le mani giunte, il volto affilato e quieto" del famoso tríptico Portinari de Hugo van der Goes en los Uffizi, esa que ella misma describió en Los imperdonables

${ }^{11}$ Monica Farnetti distingue el "núcleo esencial" formado por Leone Traverso, Gabriella Bemporad (germanistas), Margherita Pieracci (principal editora de su obra), Margherita Dalmati (poeta griega y clavicembalista), Alessandro Spina (escritor de novelas coloniales), Remo Fasano (poeta suizo), Gianfranco Draghi (psicoanalista y escritor), Vanni Scheiwiller (editor), de otro círculo de amigos, formado por Mario Luzi (poeta), Maria Luisa Spaziani, Danilo Dolci, Corrado Alvaro, Roberto Calasso, Rodolfo Wilcock, para en otro círculo situar a Guido Ceronetti, Pietro Citati, Maria Zambrano, y "de otro reino" considera a Ezra Pound, Marius Schneider, Abraham Heschel. Entre las "autoridades" cita a las ya mencionadas y en un segundo círculo a Maria Zambrano, Montaigne, Marina Tsvietaieva, Ingeborg Bachmann, Silvia Plath, Elsa Morante, a las que añade a Emily Dickinson, Christina Rossetti, Mariane Moore, Emily Brontë, Katherine Mansfiled, Virgina Wolf, Djuna Barnes, Margery Kempe, Murasaki, Christine de Pisan... (Cristina Campo, 11-14). 
como "mezza monaca, mezza fata, che adora il suo Dio col più fiorentino dei sorrisi" en un pasaje añadido posteriormente a la versión castellana de este texto en la revista Sur (Citati, "Il viso di Cristina Campo", 287-291).

Los detalles del encuentro entre Marius Schneider y Cristina Campo los desconozco. Probablemente la conferencia a la que alude la Campo en su carta a Mita de 1965 no era la primera que Schneider pronunciaba en Roma. De la vida de Schneider retendremos ahora unos pocos datos: después de haber sido acogido en Barcelona en 1943 por Higini Anglés en el Consejo Superior de Investigaciones Científicas y de haber publicado su obra más importante, El origen musical de los animales-símbolo (1946), Schneider retornó definitivamente a Alemania para ocupar la cátedra de musicología en la Universidad de Colonia en 1955. Pocos años después debió conocerlo Elémire Zolla. ${ }^{12}$ Encontramos el nombre de Marius Schneider en las primeras líneas del texto de presentación de la revista que Zolla funda en 1969, Conoscenza religiosa. En efecto, Marius Schneider es en palabras de Zolla el que "había aprendido de un viejo maestro mongol el arte del tambor ritual [...], el que supo reconocer en los capiteles de un claustro románico catalán los mismos símbolos que en la tradición india designaban las notas musicales...". Schneider se convirtió en colaborador habitual de la revista hasta su muerte en el año 1982 y Elémire Zolla publicó en Rusconi un libro, Il significato della música, en que se recogían importantes artículos de Schneider, algunos de los que se habían publicado en Conoscenza, con una introducción en la que daba cuenta de su dimensión intelectual y espiritual, de su entidad de maestro y de su capacidad de transmisión oral, y en que valoraba su obra como la obra iniciática más importante del siglo $\mathrm{xx} .{ }^{13}$

A lo largo de los catorce artículos publicados en Conoscenza religiosa entre 1969 y 1983, Marius Schneider desplegó su idea simbólica

${ }^{12}$ Acerca del paso de Marius Schneider por Barcelona cfr. Cirlot, "Notas sobre M. Schneider y J.E. Cirlot", en Rosa Cúbica, 9, 10, 11, primavera 1993, 93-107. Para una reconstrucción de la vida de Marius Schneider cfr. Bernhard Bleibinger, Marius Schneider und der simbolismo. Ensayo musicológico y etnológico sobre un buscador de símbolos, Munich, 2005.

${ }^{13}$ Cfr., Il significato della música. Simboli, forme, valori del linguaggio musicale, introduzione di Elémire Zolla, Rusconi, Milán, 1979; asimismo, el ensayo de E. Zolla dedicado en Uscite dal mondo, Adelphi, Milán, 1992, 371-382. 
de la música concebida por medio del contacto con los pueblos primitivos - en especial, africanos - y las altas culturas, la europea medieval, la india y la china. El fundamento de tal concepción se condensa en la idea de que "el sonido representa la sustancia primordial del mundo y al mismo tiempo el único medio de unión entre cielo y tierra; por ello el ofrecimiento del sonido es el sacrificio más alto" ("Le basi storiche", 273). El "en principio fue la palabra" no lo entendía como "el producto de una cultura avanzada, sino como el patrimonio conceptual más arcaico de la humanidad", advirtiendo que el concepto "palabra" sólo proporciona "parcialmente el sentido originario porque se trata de algo que genéticamente precede a cualquier palabra determinada"... En efecto, se trata de la "risa" o "grito" del dios creador, del ofrecimiento de su aliento, que es su sacrificio. El sonido como sustancia originaria de todas las cosas, "incluso ahí donde no es perceptible para el hombre ordinario" (273) es el punto de partida de todas sus investigaciones, que él no reconocía originariamente como pitagórico, sino anterior, como una idea presente ya en las culturas megalíticas. En el último artículo aparecido en Conoscenza, Schneider repetía que la primera energía sonora fue el grito-presagio del Creador y que los astros le respondieron con un canto de alabanza hecho solo de vocales, para sostener que "estos pensamientos aparecen en el tercer milenio antes de JC, fueron adoptados por Pitágoras e inspiraron a la humanidad hasta el siglo XVII. Fueron formulados admirablemente por Platón. La idea de la armonía de las esferas no habría podido conmover durante tantos siglos si no contuviera algo que llama a la intimidad del hombre" (Schneider, "Il mito del mondo primordiale", 1-9). La cosmología de Schneider se fundamenta en la sonoridad del universo y a su audición le dedicó toda su vida. En un artículo publicado en 1971 titulado "La coppia simbolica 'música e pietra", Schneider citaba el claustro de san Cugat en el que los animales corresponden a los sonidos de un canto gregoriano - uno de los capítulos fundamentales del Origen musical del 1946 publicado en Barcelona y al que hacía alusión Zolla en su editorial de Conoscen$z a$ - y se dedicaba al estudio de la pareja antitética música y piedra. La piedra es la que acoge el grito del dios para guardar en su interior el ritmo sonoro. Un oído aguzado se necesita para oír cómo "cantan las piedras" (201-213). Una audición semejante sólo puede derivar de una 
vivencia analógica por la que el cuerpo humano y su interioridad dibujan un paisaje microcósmico. Pues, en efecto, como dice Schneider, no se trata sólo de oír, sino de imitar, o de imitar para poder oír:

Para poder seguir y ejecutar ritmos en base a su disposición microcósmica el hombre debe hacerse consciente de su sustancia interior más íntima, es decir de su esencia. Según la doctrina india esta sustancia espira en los chakra, esto es, en los centros vitales que constituyen el mundo intermedio dentro del hombre. De estos çakras resonantes pocos son audibles desde el exterior, pero del mismo modo que en el Antropocosmo existe una luz interior y una exterior, hay que distinguir entre una audibilidad interna y externa ("Natura e origine del símbolo", 328).

Schneider llega a definiciones como la de que el "silencio es la concentración de las fuerzas acústicas", o la de que "el vacío es la caja de resonancia donde una fuerza atraída se eleva como un canto" ("Musica e lingua sacra", 114-115). Pero no vamos ya a ahondar más aquí en la compleja musicología de Marius Schneider. Baste ahora sólo haber invocado su presencia en el círculo romano frecuentado por Campo, en las revistas en que colaboraban ambos, la argentina Sur y la italiana Conoscenza religiosa, para que la expresión de Boris Pasternak, "el oído del alma" adquiera unos contenidos precisos en los que el valor metafórico se diluye para dar paso a la realidad simbólica. Unos contenidos a los que no era ajena María Zambrano, al menos la de Claros del bosque, pues aunque la Zambrano había abandonado Roma en 1964 para trasladarse a La Pièce siguió en contacto epistolar con Campo, con Zolla, y con toda probabilidad fue recibiendo Conoscenza religiosa, justamente en donde publicó La fiamma, dedicado a Vittoria-Cristina in memoriam en el número de octubre-diciembre de 1977, meses después de la muerte de Vittoria Guerrini/Cristina Campo, en la noche entre el 10 y el 11 de enero de aquel año.

A María Zambrano se debe una frase que podría haber encabezado Il flauto e il tappeto. En ella se alude a la superioridad de la audición sobre la visión, aunque al mismo tiempo se afirma el milagroso nacimiento de la figura allí donde sólo había manchas. Esa frase que condensa de un modo extraordinario el contenido del ensayo de la Campo es: "La voz del destino se oye mucho más de lo que la figura del destino se 
ve". ${ }^{14}$ La encontramos en las primeras páginas de Claros del bosque (1977) y no se va a quedar ahí sin más, sino que anuncia las reflexiones de Zambrano acerca del sonido, de la palabra, de la voz, del oído, que se esparcirán por todo el libro. Así, por ejemplo, la idea "sinfónica" del alma (anima est symphonialis) la expresa así: "Parece así tener [el alma] un íntimo parentesco con la palabra y con algunos modos de la música; fundamento mismo, que se nos figura, de toda liturgia" (Zambrano, Claros del bosque, 31-32). La urgencia del oído interior ("Hay que escuchar más finamente") la persigue y la obliga a pensar en lo que suena y lo que no suena, como por ejemplo: "Centro también el corazón porque es lo único que de nuestro ser da sonido. Otros centros ha de haber, mas no suenan" (64). O también: "Y es la voz interior que se identifica con algunas voces, con algunas palabras que se escuchan no se sabe bien si dentro o fuera, pues que se escuchan desde adentro. Y se sale también a escucharlas, se sale de sí" (67). Decididamente schneideriana es la consideración de que "no hay historia sin palabra, sin palabra escrita, sin palabra entonada o cantada — ¿cómo iba a decirse palabra alguna sin entonación o canto? [...] ¿Y aquella piedra tan igual a las otras, no podría ser ella, ser la que canta? Pues en las piedras ha de estar el canto perdido", y sólo cinco páginas más adelante: "Porque la música es, desde un principio, lo que se oye, lo que se ha de oír, y sin ella, la palabra sola decae adensándose, camino de hacerse piedra, o asciende volatilizándose, defraudando" $(92,97)$. No conozco a nadie, si no es Marius Schneider, que haya dicho que la música se hace piedra, que el sonido es acogido por la piedra, que las piedras cantan.

Il flauto e il tappeto: ése es el título que Cristina Campo dio a su libro publicado por Rusconi en 1971. En él recogía algunos de los textos que ya había publicado en Vallecchi nueve años antes, con el título de Fiaba e mistero, y añadía otros nuevos. Gli imperdonabili, póstumamente publicados por Adelphi en 1987, añadía a Il flauto e il tappeto los que no fueron publicados de Fiaba e mistero y otros textos escritos entre 1971

${ }^{14}$ A la importancia de la música para ambas escritoras también alude Annarosa Buttarelli, cfr. "Nel nome di una rosa. L'incontro tra Cristina Campo e María Zambrano", Appassionate distanza. Letture di Cristina Campo con una scelta di testi inediti, Tre Lune edizione, Mantua, 2006, 303-318, y en particular, 307 donde cita Notas de un método de la Zambrano. 
y 1977. El sonido y la figura, audición y visibilidad, son los ejes que ordenan todo el libro y por los que adquiere una contundente unidad. Aunque la verdadera unidad procede de eso que tanto le preocupaba, eso que llamamos "estilo" y que no es sino el traslado difícil y costoso con apariencia de absoluta facilidad, de un sonido, de un rumor, una murmuración interior, la propia, ahí donde reside la auténtica identidad de la persona y la hace inconfundible. En unas palabras preliminares Cristina Campo alude al carácter sólo aparentemente variopinto del libro para insistir en su unidad y compararlo a una camara dipinta. Pero a ese esfuerzo de hacer visible lo invisible, se añadía también el de hacer audible lo inaudible. En una variante a estas palabras preliminares que encontramos en una carta a Mita, leemos:

Escribo el libro de ensayos que quisiera titular "La flauta y la alfombra". Son dos imágenes del destino, una según el salmista (37), otras según varias tradiciones (también Hoffmannsthal la recoge en la famosa imagen de la alfombra de la vida). Quisiera en realidad que no se tratara de un libro de ensayos sino de un solo discurso en varios tiempos, como una serie de piezas musicales donde siempre vuelven los mismos temas y las mismas palabras. O bien una "camara picta" con los mismos paisajes y personajes vistos sucesiva y circularmente (Lettere a Mita, 247).

Es a esa dimensión musical del libro a donde queremos llegar. Comenzaremos por una escena de la infancia reconstruida por Cristina de Stefano en su biografía, aquella en la que ella oye tocar a sus padres a cuatro manos:

Cristina Campo ama la música. Su padre es compositor, su madre toca el pianoforte. Una de las primeras imágenes de su infancia son sus padres tocando a cuatro manos. Para ella la música no es de fondo sino presencia que excluye todo el resto. Hay que oírla, como enseña Simone Weil, con una atención privada de deseo. En torno a la música construye en sus textos intuiciones que tienen algo de pitagóricas: la amistad como sutil equivalencia musical, el destino como melodía para reconocer por el camino. Se formó sobre todo con los madrigalistas ingleses adorados por su padre - Wilson, Bull, Johnson - con sus pavanas severas $[\ldots]$ ama Bach [...] Mozart "que lo sabe todo y lo dice todo", Gesualdo 
da Venosa... Sobre todo ama a Chopin, el más elegante, su maestro en sprezzatura (Stefano, Belinda e il mostro, 106).

palabra intraducible en castellano, y clave en la estética de la Campo, herencia de Castiglione, y que alude a una forma de hacer en que todo ha de parecer ligero, flexible, sobre todo cuando se trata de cosas muy importantes. En su definición, sprezzatura "es un ritmo moral, la música de una gracia interior" (100) y es la comparación musical la que le permite alcanzar su esencia

alla delicata, feroce geometría che rende possibile la danza della libellula assimileremo la sprezzatura? O all'inflessibile metrónomo, sempre terzo e sempre in moto nelle lezioni di Federico Chopin, sul quale si misuravano impietosamente le tenerezze et le turbolenze, i rubati, i turbati, l'estassi stessa e il trafiggente presentimento? Che la mano sinistra sia il vosotro maestro di capelle e conservi sempre la misura", ammaestrava questo Racine del pianoforte, intolerante di pedali, glissandi, rallentandi, sonorità in aumento, passioni, rivluzioni, rivendicazioni. "Che nulla traspaia dell'intimo cuore, nulla sia noto di noi che il sorriso" [...] "Facilement, facilement", era la sua parola tematica mentre, passeggiando avanti e indietro per la stanza, un fazzoletto intriso di colonia sulla labbra o sorseggiando acqua gommata per poter parlare, inchiodava gli allievi a quel trattato di ascética, il clavicémbalo ben temperato (104).

Y así cuando lee a Proust, Cristina Campo oye "la mezcla de un terrible movimiento descendente del tiempo, y de un contrapunto ininterrumpido ascendente de la palabra", para de inmediato compararlo con ciertos pasos de Beethoven para pianoforte, donde "la melodía continúa a subir en altura y transparencia mientras el bajo desciende cada vez más en las tinieblas" (162) Las equivalencias entre música y escritura que Cristina Campo encuentra en la lectura, funcionan exactamente igual en su creación: su prosa es musical, pues como analizara Monica Farnetti, "está gobernada más por una lógica pianística mucho más que gramatical" (Cristina Campo, 25). Ya Elémire Zolla, cuando apareció Gli imperdonabili en Adelphi aludió en su reseña al arte del "ricalco musicale" y a los maravillosos ejemplos que en el libro pueden encontrarse de ese arte ("La verità in uno stile", 284). En el coloquio dedicado 
a la Campo en 1998, Filippo Secchieri comentaba del mismo libro su organización en bloques paratácticos, desvinculados de la progresión causal, la absoluta autonomía de cada período, la centralidad de cada frase y su disposición en círculos concéntricos, formando así composiciones concéntricas y también "decéntricas", según el neologismo creado por la propia Campo para hablar de John Donne ("L'arabesco saggistico", 128-140). También en ese volumen, Alba Donati comentaba la prosa de Los imperdonables como un "vocabulario de palabras extinguidas, con un ritmo narrativo que es el ritmo de las estaciones, el del gregoriano, el de la liturgia bizantina, porque procede por solemnes elevaciones, pausas y altísimas repeticiones. $\mathrm{O}$ bien procede por increíbles concentraciones donde Chopin convive con los inciensos y las llamas de Bizancio" ("Cristina Campo, l'Assente", 145). Pero veamos un ejemplo, la última página del ensayo que concede título al libro, Los imperdonables:

Si vede talvolta in un treno, in una sala d'aspetto, un volto umano. Che ha di diverso? Di nuovo potremmo dire ciò che quel volto non ha, ciò che i suoi tratti non tradiscono. Gli occhi non diffidano né sollecitano, non divagano e non indagano. Occhi in nessun attimo assenti, mai interamente presenti. Ai giorni nostri tali volti, comuni nei quadri antichi, sembrano sigillati da una invincibile malinconia. Pure, nel treno, nella sala d'aspetto, essi gonfiano l'animo di gioia, di un accresciuto, appunto, sentimento di vita. Non correrà parola, ma il puro, subitáneo sorriso è fuga in un tranquillo luogo, vulnerabile al punto da essere inattingibile. Si dice, rápidamente: "Occhi consapevoli". Sono, in realtà occhi eroici. Hanno guardato la belleza e non ne sono fuggiti. Hanno riconosciuto la sua perdita sulla terra, e in grazia di ciò l'hanno guadagnata alla mente. Neppure la fotografía può interamente distruggere tali volt $i$, di più in più rari, è vero. Muta la razza, muta ormai la specie, tra poco tali volti saranno appena percepiti e, percepiti, anch'essi imperdonabili, tanto estranei al contesto, al sistema che li racchiude. Già cominciano a farsi invisibili, come il Graal e la lancia di Longino che una mano riportò al cielo, si dice, quando gli uomini non furono più degni di custodirli; come il cinese che leggeva un libro e su cui la folla súbito si richiuse. 
El tema del pasaje es el rostro (volto), pues el imperdonable se ve, se reconoce. El término aparece repetido en estas catorce líneas cinco veces, dos en singular y tres en plural. La sonoridad de la $\mathbf{v}$ domina en la primera frase en una secuencia aliterativa vede/talvolta/volto/diverso/ nuovo, para combinarla con otras aliteraciones tratti/tradiscono, y dar entrada a un nuevo término, el otro repetido en el pasaje: ojos (occhi) que aparece tres veces. Las aliteraciones se combinan con rimas internas (divagano/indagano). Se repiten expresiones de entre las cuales la más significativa sea in un treno, in una sala d'aspetto (líneas 1 y 5). Variantes homofónicas (pure/puro/neppure), estructuras paratácticas (hanno guardato/hanno riconosciuto; muta la razza/muta ormai la specie), todo ello prepara el oído para la comparación final, absolutamente inesperada, insólita, la del Grial, y la recuperación de la imagen del chino en la cola con la que se comenzó el texto páginas atrás y que ya está a punto de terminar. Esto es únicamente un ejemplo, pero la lectura de la Campo exige de la atención necesaria para oír sus frases, densas, concentradas. Son las frases de una poeta que escribe prosa, lo que como decía Joseph Brodsky en su espléndido análisis sobre Tsvietáieva constituye la gran suerte de la prosa: “¿Qué aprende un prosista de la poesía? La dependencia de la gravedad concreta de una palabra respecto de su contexto, la concentración mental, la omisión de lo evidente, los peligros que acechan a quien se encuentra en un estado mental elevado. ¿Y qué aprende el poeta de la prosa? Poca cosa" ("Una poetisa y la prosa",160).

Es en el texto titulado La flauta y la alfombra (1971) donde Cristina Campo concentra la idea del oído interior como el más privilegiado de los sentidos. La pregunta de "Potrebbero, d'altra parte, creature che furono mutílate dell'organo stesso del mistero - Pasternak direbbe l'orecchio dell'anima - riconoscere di aver perduto il proprio destino?" (113), nos introduce de lleno en el tema abordado en el ensayo. El oído perfecto que imploran los salmistas no es sino el órgano necesario para oír la "llamada", la "vocación" que construye el destino, de pronto visible a través de la figura. Pero la figura del destino se teje en la alfombra al ritmo que marca el sonido de la flauta: 
Gli anelli dócilmente svolti e riavvolti dalle aspidi sante vengono ad intrecciarse da soli in questa semplice allegoria, ricca di splendori: il flauto dell'incantatore intesse e annoda aspidi come la mano del tessitore stami. Ma non c'e allegoria che la realtà non racciuda. I portentosi 'maestri del tappeto", quei bardi e mistici del telaio che anticamente passavano di villaggio in villaggio e custodivano nella mente centinaia di schemi simbolici, ne 'dettavano' le figure ai tessitori local con una lenta salmodia ammaliante. E poichè quelle estese, rosee miniature, $i$ tappeti dei Senneh, erano dovuti a dita di bimbi — le sole capaci dei annodar nodi di così mágica piccolezza - per avvincere all'incantesimo le giovani menti ritmava il lavoro l'ardente voce del flauto (115).

Advierte de inmediato de lo imperceptible del sonido de la flauta:

Certo, la voce del flauto è remota. È quasi sempre quasi imperceptibile. Terribilmente tramata alle mille voci del tempo, alle musiche discordemente streganti del concertó mundano. Come un suono percepito in sogno, come la voce dell'usignoletto minúsculo, il cui dardo di diamante farà tacere tutti i suoni del bosco, è il suo delicato lamento (136).

El oído capacitado para semejante audición que ya es una contemplación, sólo puede forjarse con la ascesis de la atención:

Chi trasale a quell'esile trafittura conosce la contemplazione dell'udito. Ciò richiede una dureza affilita nell'ascesi dell'attenzione, perchè quel suono è di continuo travolto via, lacerato e dispero dal sibilo del perceptibile e niente è più facile che crederlo una morgana dell'orecchio. Altre voci, altri flauti simulano continuamente quel fuoco che si è morti se non si ode, e senza dubbio i concerti spuri furono di rado più persuasivi di oggi (136).

Cuando la Campo habla del destino, lo hace entendiéndolo como algo sagrado:

In realtà ciò che fa del destino una cosa sacra è lo stesso elemento che distingue il sacro, lo stesso che distingue la poesía: la sua seclusione, segregazione, l'estatico vuoto in cui si compie. [...]La scena del destino è cóncava, tacita e risuonante come la casa di un prezioso strumento; è 
il 'liuto sospeso' di Poe. Vi erano luoghi, una volta, dove la gente si ritirava 'per veder chiaro in se stessa', il che non mi sembra significhi altro che riaddestrare l'orecchio al susurro affilato del flauto, al sordo allarme della spola (118).

Estos pasajes, verdaderamente extraordinarios en lo que respecta a la comprensión de la idea de destino que bien podrían prologar los cuentos de una Isak Dinesen por la coincidencia en el sentimiento de la vida, aluden al misterio al que quiso enfrentarse Marius Schneider. Dibujan un paisaje que hace visible esa sonoridad interior. Un paisaje en el que una y otra vez oímos aquel koan zen que tanto le gustaba a Campo, y que recomendaba no fiarse de la propia percepción hasta no haber oído el aplauso de una sola mano.

\section{REFERENCIAS}

Brodsky, Joseph, "Una poetisa y la prosa", en Menos que uno. Ensayos escogidos, Madrid, Siruela, 2006.

CAMPo, Cristina, "Atención y poesía”, María Zambrano (trad.), Sur, 271, julio y agosto 1961, 38-41; "In medio Coeli", trad. Pedro J. Albertelli, Sur, julio y agosto 1962, pp. 30-40; "Les sources de la Vivonne", trad. M.L. Bastos y Eugenio Guasta, Sur, marzo y abril 1964, "Los imperdonables", Sur, julio y agosto 1966.

CAMPO, Cristina, La flauta y la alfombra, Milán, Rusconi, 1971.

CAMPo, Cristina, Lettere a un amico lontano, Milán, Scheiwiller, 1989.

CAMPo, Cristina, "Il mundus imaginalis", en Per Cristina Campo, Monica Farnetti y Giovanna Fozzer (eds.), Milán, Vanni Scheiwiller, 1998.

CAMPO, Cristina, Lettere a Mita, Margherita Pieracci Harwell (ed.), Milán, Adelphi, 1999.

CAmpo, Cristina, Caro Bull. Lettere a Leone Traverso [1953-1967], Milán, Adelphi, 2007.

CAmpo, Cristina, Se tu fossi qui. Lettere a Maria Zambrano [1961-1975], Maria Pertile (ed.), Milán, Archinto, 2009.

Citati, Pietro, "Il viso di Cristina Campo", en Ritratti di donne, Milán, Rizzoli, 1997.

Donati, Alba, "Cristina Campo, l'Assente", en Per Cristina Campo, Monica Farnetti y Giovanna Fozzer (eds.), Milán, Vanni Scheiwiller, 1998.

Farnetti, Monica, Cristina Campo, Ferrara, L. Tufani, 1996. 
SCHNEIDER, Marius, "Consideraciones acerca del canto gregoriano y la voz humana", Sur, 292, enero y febrero, 1965, 4-20.

SCHNEIDER, Marius, "Le basi storiche della simbología musicale", Conoscenza religiosa, III, 1969, 267 ss.

Schneider, Marius, "Natura e origine del símbolo", Conoscenza religiosa, Iv, 1971a, 313 ss.

SCHNEIDER, Marius, "La coppia simbolica 'musica e pietra'. Saggio di decifrazione di un pensiero filosofico espresso con un simbolo de natura rituale" Conoscenza religiosa, II, $1971 \mathrm{~b}$.

SCHNEIDER, Marius, "Musica e lingua sacra nella tradizione vedica", Conoscenza religiosa, $\mathrm{I}, 1973,111 \mathrm{ss}$.

SCHNeIDer, Marius, Il significato della música. Simboli, forme, valori del linguaggio musicale, introduzione di Elémire Zolla, Milán, Rusconi, 1979.

SCHNEIDER, Marius, "Il mito del mondo primordiale e l'armonia delle sfere", Conoscenza religiosa, I, 1983, 1-9.

SCHNEIDER, Marius, "Le basi storiche della simbología musicale", Conoscenza religiosa, III, 1969.

Secchieri, Filippo, "L'arabesco saggistico", en Per Cristina Campo, Monica Farnetti y Giovanna Fozzer (eds.), Milán, Vanni Scheiwiller, 1998.

Stefano, Cristina de, Belinda e il mostro. Vita segreta di Cristina Campo, Milán, Adelphi, 2002.

Spina, Alessandro, Conversazione in piazza sant'Anselmo, Milán, Scheiwiller, 1993.

Zambon, Francesco, “'Il mundus imaginalis' de Cristina Campo”, en Per Cristina Campo, Monica Farnetti y Giovanna Fozzer (eds.), Milán, Vanni Scheiwiller, 1998, 18-23.

Zambrano, María, Claros del bosque, Barcelona, Seix Barral, 1978.

ZoLlA, Elémire, Uscite dal mondo, Milán, Adelphi, 1992, 371-382.

Zolla, Elémire, "La verità in uno stile", en Corriere della Sera, 15 de noviembre 1987. 